\title{
DESAFIOS DO ENSINO SUPERIOR PARA ESTUDANTES DE ESCOLA PÚBLICA: UM ESTUDO NA UFLA
}

\author{
THE HIGHER EDUCATION CHALLENGES FOR STUDENTS OF PUBLIC SCHOOL: A STUDY IN THE UFLA \\ DOI: http://dx.doi.org/10.12712/rpca.v6i1.110
}

\author{
Carolina Faria Alvarenga \\ Universidade Federal de Lavras \\ carol alvarenga@ded.ufla.br
}

\section{Aline Pereira Sales}

Universidade Federal de Lavras

lininhalvs@yahoo.com.br

\author{
Adriano Dias da Costa \\ Maurício Donizete da Costa \\ Ricardo Braga Veroneze \\ Thiago Lima Bahia Santos
}

Universidade Federal de Lavras

\section{RESUMO}

Este trabalho busca compreender os desafios enfrentados por estudantes vindos de escolas públicas, por meio da análise, em específico, do curso de Administração da Universidade Federal de Lavras, entre 2005 a 2010. Para tanto, utilizou-se de uma abordagem predominantemente qualitativa, a partir de questionários semi-estruturados e de um grupo focal. Os resultados obtidos revelaram que a formação do estudante de escola pública é permeada por dificuldades, dentre as quais, destacam-se a falta de estrutura e recursos, a desmotivação dos professores, o desinteresse dos alunos, seja pelo cansaço físico ou pela falta de perspectivas para o futuro. Não obstante, o distanciamento com a universidade e a falta de divulgação das oportunidades existentes fazem do ensino superior uma realidade distante para a maioria desses estudantes. Ainda assim, muitos egressos do ensino público conseguem ter acesso ao ensino superior, sendo que, depois de inseridos, conseguem ter o mesmo padrão de aprendizagem daqueles que vieram de escola privada. Entretanto, continuam a enfrentar dificuldades que, até certo ponto, exigem ainda mais esforço destes estudantes. Neste sentido, iniciativas em prol da permanência desses jovens nas universidades fazem-se fundamentais. Além de medidas conjuntas entre governo e universidade que visem a educação, outras políticas públicas precisam caminhar junto às educacionais a fim de que, ao entrarem no mercado de trabalho, esses egressos tenham as mesmas oportunidades.

Palavras-chave: Desafios. Estudantes de escola pública. Acesso. Permanência. Educação Superior

\begin{abstract}
This article aims to understand the challenges that public school students face in attempting to enter and remain in public universities. For such, questionnaires were responded by students of the Federal University of Lavras and a focus group was conducted with some of them. The results revealed that the public school education has peculiar difficulties for this type of schooling which, in addition to the distance between schools and universities and the lack of information, make the Higher Education a distant reality for most of these students. Despite all obstacles, some of those who finished public highschool succeed in being admitted to Higher Education, since they go through financial problems which require those students to make greater efforts. Consequently, public policy must be in tune with educational policy so that, when getting a job in the labor market, undergraduates will have equal opportunities.
\end{abstract}

Keywords: Challenges. Students from public school. Access. Permanence. Higher Education 


\section{Introdução}

O papel das Instituições de Ensino Superior (IES), cada vez mais, ganha importância no meio estudantil, visto que a globalização entoou ritmo e intensidade à evolução do conhecimento e da ciência de um modo geral. Neste contexto, ingressar em uma universidade representa, para muitos jovens, um grande passo para inserção no mercado de trabalho, cada vez mais competitivo. Entretanto, observa-se que, para muitos estudantes, a formação superior não passa de um sonho, cujas barreiras de acesso parecem intransponíveis.

Apesar de haver ocorrido na década de 90 um significativo aumento de vagas no vestibular na rede pública de ensino, foi na rede privada que ele atingiu o maior percentual de aumento: 147,9\%. Tal fato indica que um significativo número de jovens não tem acesso ao ensino público e gratuito, restando-lhe somente a opção de pagar seus estudos de nível superior. A rede privada, desde 1990, oferece, aproximadamente, $70 \%$ das vagas no vestibular e, o conjunto da rede pública, 30\% (SOARES, 2002, p.115).

Começando pelas altas relações candidato/vaga das universidades públicas e passando pela falta de recursos financeiros para arcar com os custos do ensino privado, os estudantes de escola pública, que representam a maioria dos estudantes do ensino médio, passam a representar uma minoria no ensino superior. Desta forma, entende-se que exista uma maior preparação por parte dos estudantes advindos da rede privada de ensino, que faz com que consigam ter acesso às universidades públicas com maior facilidade que os demais.

De acordo com Buarque (2003, p. 3), ainda que o contexto mundial tenha sofrido grandes transformações "em termos de informação, conhecimento e novas técnicas de comunicação e educação", ao longo dos anos, poucas foram as mudanças estruturais nas universidades, o que evidencia "a necessidade de revolução no conceito de universidade". Logo, fica visível a necessidade de adaptação do modelo de formação oferecido pelas universidades para que as demandas existentes na sociedade contemporânea sejam correspondidas e também que o ensino superior esteja acessível a toda a população, o que, para tanto, requer conhecimento e reflexão sobre o assunto.

Desta forma, assumindo-se que o ensino superior brasileiro ainda não se encontra democratizado, busca-se, neste trabalho, compreender os desafios enfrentados por estudantes vindos de escolas públicas para ingressar e permanecer no ensino superior público, por meio da análise, em específico, do curso de Administração da Universidade Federal de Lavras, no período compreendido entre 2005 a 2010. Para tanto, será averiguado se, de fato, estudantes vindos de escola pública representam uma minoria nesta IES e se estes apresentam menor rendimento acadêmico, se comparado aos demais.

Assim, acreditamos que, conhecendo melhor a realidade destes estudantes e os desafios enfrentados por eles, tem-se maior embasamento para discussão do assunto e avaliação de formas de se garantir a igualdade de acesso e de permanência no ensino superior a todos os estudantes. Conforme coloca Zago (2006, p. 236), "estudar essa população para entender as transformações nas demandas e nas práticas escolares, assim como no perfil dos estudantes na sociedade contemporânea, representa uma necessidade para a pesquisa e as políticas educacionais em todos os níveis de ensino".

Antes de iniciarmos a problematização dos desafios enfrentados pelos estudantes do curso de Administração da Universidade Federal de Lavras (UFLA), apresentamos um breve panorama da conjuntura educacional brasileira, em relação ao número de vagas nas IES, e a realidade do 
estudante de escola pública do Brasil.

\section{O ensino superior no Brasil e suas barreiras de acesso aos estudantes de escola pública}

A década de 1960 foi marcada pela ampliação de vagas no ensino superior brasileiro via privatização o que, no entanto, não foi suficiente para fazer com que o país deixasse de possuir uma das mais baixas taxas de escolarização bruta na Educação Superior da América Latina. Este processo apresentou como conseqüência, uma elitização do perfil dos alunos, principalmente nos cursos mais concorridos e nas instituições privadas, onde é muito pequena a presença de alguns grupos, que podem ser considerados como minorias. Devido ao alto grau de privatização, quando comparado a outros países, acredita-se que uma expansão do setor público seja uma das possíveis saídas (PINTO, 2004).

Em seu trabalho, Neves, Raizer e Fachinetto (2007) levantam pontos relacionados à questão da equidade social no ensino superior brasileiro. Após a década de 1970, período de alavancagem do ensino superior, o Brasil teria estagnado o desenvolvimento da rede pública, dando espaço à rede privada, onde alunos provenientes de camadas sociais mais bem sucedidas teriam mais espaço, devido às condições socioeconômicas oferecidas por suas famílias. Segundo os autores, o país apresenta tendências de melhorias, mas esse contexto ainda não sofreu grandes mudanças.

Para Ortega (2001), o elitismo do acesso ao ensino superior brasileiro está mais relacionado à preparação dos alunos por parte de suas escolas do que ao processo seletivo em si. As escolas particulares dessa elite estariam mais interessadas em preparar seus alunos para as boas universidades públicas, enquanto as escolas públicas não disponibilizam sequer informações necessárias sobre o ingresso aos seus estudantes. A autora destaca que os principais benefícios dos alunos de escola particular são: a) o fato de estarem previamente decididos a se inscreverem nos vestibulares a fim de tentar o ingresso; b) o fato de estarem informados sobre os vestibulares de diferentes universidades; c) o fato da estrutura educacional pública básica não incentivar seus alunos a tentar o ingresso nas universidades;

d) as vantagens econômicas e sociais, conseqüentes da desigualdade social, que estes alunos dispõem (ORTEGA, 2001).

Os resultados e prospecções do Índice de Desenvolvimento da Educação Básica (Ideb), disponibilizada pelo Instituto Nacional de Estudos e Pesquisas Educacionais (Inep), elucida a discrepância entre a eficiência do ensino público e privado no Brasil, que chegou a ser de 2,7 nos ensino fundamental e médio, o que representa uma grande lacuna na educação do país. Esta desigualdade, conforme as metas estipuladas para 2021, tende a continuar, na ordem de 2,2, o que significa que os alunos de ensino público brasileiro continuarão em condição de desvantagem perante seus concorrentes do ensino privado ao disputar uma vaga no vestibular.

Segundo Vasconcelos (2004), alguns fatores comprometem a rede de escolas públicas de educação básica quando analisados em conjunto, como: infraestrutura, material de apoio didático, segurança nas escolas, motivação discente e docente (práticas pedagógicas adequadas), remuneração e atualização de profissionais da área. Tais fatores de natureza complexa estimulam o surgimento de obstáculos ao desenvolvimento do setor, reduzindo a "competitividade" do aluno de origem de escola pública quando comparado ao aluno de escola particular.

Ao analisarmos o número de matrículas na educação básica brasileira entre 2002 a 2010, 
nota-se uma ascendência no número de matrículas da rede privada (de 7.184 para 7.560), em detrimento a uma relativa queda do número de matrículas da rede pública (de 49.019 para 43.990), apesar de o número total de matrículas ser predominantemente do setor público. 0 número de candidatos ao ensino superior no país também cresceu significativamente entre 2001 a 2007, o que, por sua vez, fez com que a relação candidato/vaga por curso também obtivesse considerável alta, visto que a oferta de vagas, no mesmo período, não acompanhou tal crescimento na mesma proporção.

A oferta insuficiente de vagas torna-se ainda mais grave ao analisarmos especificamente o setor público. Segundo dados do Censo da Educação Superior (MEC /INEP, 2010), o número de instituições públicas cresceu 3,8\% de 2008 para 2009, enquanto o número de instituições privadas cresceu $2,6 \%$ no mesmo período. No entanto, a rede privada ainda ocupa $89,4 \%$ do setor, o que dificulta ainda mais o ingresso em instituições de ensino públicas, haja vista o grande número de candidatos às poucas vagas oferecidas. Esse aumento da concorrência faz com que a seleção de candidatos passe a ser ainda mais criteriosa, exigindo por parte dos candidatos uma preparação ainda melhor.

Faz-se importante salientar que a expansão no número de IES brasileiras não representou uma forma de promoção do acesso de estudantes oriundos de segmentos sócio-econômicos mais baixos, visto que a composição social dos estudantes do ensino superior se manteve praticamente inalterada (NEVES, RAIZER E FACHINETTO, 2007). Dados do PNAD/IBGE de 2004 revelam que a concentração de estudantes pertencentes à parcela mais rica da população, que representam apenas $9,6 \%$ das famílias brasileiras, é superior a $50 \%$ tanto na rede pública quanto na rede privada, ao passo que "apenas 2,3\% e 1,2\% são ocupadas, no ensino público e privado respectivamente, por estudantes mais pobres, [..] que correspondem a 30,2\% das famílias do País" (NEVES, RAIZER E FACHINETTO, 2007, p. 146).

Uma análise da origem dos alunos ingressantes nas instituições de Ensino Superior público evidencia uma participação pouco expressiva por parte dos alunos que cursaram o ensino médio público em relação aos alunos vindos de escolas privadas, mesmo o primeiro grupo representando a maioria dos estudantes brasileiros, segundo o Censo Escolar de 2010 (MEC/INEP, 2010). Do total, 88,2\% dos estudantes brasileiros matriculados no ensino médio no ano de 2010 passaram por escolas públicas, ao passo que apenas 11,8\% passaram por escolas particulares. Pode-se observar que tal distribuição encontrada no ensino médio não se apresenta de maneira proporcional quando analisamos o ingresso dos estudantes nas universidades públicas.

Faz-se relevante observar que, para as carreiras de maior prestígio social, as quais a concorrência para o ingresso é ainda mais alta que as demais, os números resultantes das comparações entre a origem de rede pública e privada assumem um caráter ainda mais discrepante. Na Universidade Federal de Lavras, por exemplo, enquanto que, para um curso de maior prestígio e, consequentemente, maior concorrência como o de Agronomia, o número de estudantes advindos de escolas públicas não chegou a $27 \%$ do número total, no período entre 2007 a 2010, para um curso noturno e de menor prestígio social e concorrência, como o de licenciatura em Educação Física, o número de estudantes de escola pública representou $51 \%$ do total, no mesmo período.

Esta mesma constatação, por parte da Universidade Federal da Bahia (2005), fez com que a instituição optasse, no ano de 2004, pela criação de políticas de cotas, visando a redução da desigualdade entre estudantes de escola pública e privada. Como as universidades públicas apresentam autonomia, não há um consenso quanto à adoção ou não de políticas afirmativas 
e/ou reparatórias aos percentuais adotados.

No escopo deste trabalho, que abrange apenas a Universidade Federal de Lavras, ainda não foi implementada nenhuma política afirmativa ou reparatória, cujo objetivo fosse garantir o acesso e, sobretudo, a permanência de grupos social, cultural e economicamente desfavorecidos. Convém salientar, porém, que nosso recorte centrou-se apenas em estudantes oriundos de escolas públicas. Apesar de considerar como pressuposto teórico de que os marcadores sociais, tais como gênero, raça/etnia, classe social, orientação sexual, religião, entre outros, influenciam na trajetória individual dos estudantes, estes não foram conceitos centrais em nossas análises.

\section{Método}

Com o propósito de compreender os desafios enfrentados por estudantes vindos de escolas públicas para ingressar e permanecer na UFLA, procurou-se, neste trabalho, entender o problema de pesquisa sob a perspectiva desses alunos, utilizando-se, para tanto, uma abordagem predominantemente qualitativa. A escolha desse método encontra respaldo na afirmação de Gondenberg (2007, p. 63), de que, esse tipo de pesquisa consegue "estudar questões difíceis de quantificar, como sentimentos, motivações, crenças e atitudes individuais".

Todavia, para que fosse possível chegar à conclusão de que, de fato, os estudantes de escola pública representam uma minoria dentro da universidade, e para compreender como se dá o desempenho desses alunos dentro da academia, foi necessário lançar mão de alguns métodos quantitativos, como a análise do número de estudantes vindos de escolas públicas e privadas, no período de 2005 a 2010, e a distribuição das médias dos Coeficientes de Rendimento Acadêmico (CRA) semestral desses alunos, no mesmo período. 0 CRA é o método de avaliação utilizado pela Universidade para quantificar o desempenho dos alunos ao longo dos semestres. Seu cálculo se dá por meio da média das notas do semestre, ponderada pela carga horária da disciplina (disciplinas com maior carga horária recebem peso maior).

Os dados para realização destas análises iniciais foram cedidos pela Diretoria de Registro e Controle Acadêmico da Universidade, mediante prévia aprovação do Pró-Reitor de Graduação, e continham o número de matrícula do estudante, a escola em que cursou o ensino médio, ou a maior parte dele, a classificação desta como pública ou privada e os CRA dos alunos ao longo dos semestres por ele cursados na graduação.

Após verificação quantitativa dos alunos, de todos os cursos que existiam há mais de cinco anos na Universidade, os dados foram filtrados, restando apenas os estudantes do curso de Administração oriundos de escola pública. Assim, a partir do número de matrícula desses, conseguiram-se, no Departamento de Administração e Economia (DAE), o nome, o telefone de contato e o email destes estudantes para realização da etapa seguinte.

Neste segundo momento, utilizou-se de um questionário semi-estruturado, tipo Survey, contendo 48 questões (sendo 31 fechadas e 17 abertas), para compreender melhor se, de fato, os estudantes de escola pública se sentiam prejudicados perante os demais estudantes e se, de fato, acreditavam ter enfrentado maiores desafios antes e/ou ao longo da graduação. Para tanto, buscou-se avaliar a opinião de todos os alunos do curso de Administração vindos de escola pública, matriculados no período entre 2005 a 2010. Todavia, o baixo retorno de respostas inviabilizou a aplicação dos questionários em toda amostra. Assim, dos 87 alunos vindos de escola pública pertencentes ao curso de Administração, 26 responderam a esta 
pesquisa. Como ferramenta para envio do questionário, foi utilizado o Google Docs.

A fim de discutir e pormenorizar a temática e os resultados obtidos com a análise dos questionários, realizou-se um grupo focal com os estudantes. Segundo Dias (2000, p. 3), “o objetivo central do grupo focal é identificar percepções, sentimentos, atitudes e ideias dos participantes". Assim, foram convidados 10 alunos do curso de Administração, sendo um representante de cada turma. Como critério de seleção dos estudantes pertencentes à mesma turma, buscou-se analisar as respostas dadas nos questionários, de forma a priorizar aqueles que contribuíram mais com a pesquisa em opiniões. Entretanto, em virtude de os alunos das turmas de 2005 a 2007 já terem se formado e os da primeira turma de 2008 já terem saído para estágio obrigatório, não foi possível alcançar uma amostra com representantes de todas as turmas, sendo realizado o grupo focal com nove estudantes, que ingressaram na Universidade a partir do segundo semestre de 2008.

\section{0 acesso e o rendimento acadêmico de estudantes do ensino público na UFLA}

As disparidades entre estudantes de baixa renda e estudantes de condição financeira mais elevada, vão muito além de fatores estritamente econômicos, caracterizando-se também como desigualdades de oportunidade entre as classes sociais. Esta discrepância, por sua vez, faz da seleção de candidatos às universidades públicas um processo predominantemente elitista, que limita as possibilidades de ingresso dos estudantes advindos de escolas públicas (VASCONCELOS E LIMA, 2004).

Neste contexto, surge o Programa de Apoio a Planos de Reestruturação e Expansão das Universidades Federais (Reuni), "com o objetivo de criar condições para a ampliação do acesso e permanência na educação superior, no nível de graduação, pelo melhor aproveitamento da estrutura física e de recursos humanos existentes nas universidades federais" (BRASIL, 2007).

Na UFLA, a proposta adotada consiste em três grandes eixos: o aprofundamento da flexibilização curricular e das inovações pedagógicas, a ampliação da oferta de vagas (de 840 em 2007 para 1480 em 2011 - aumento de 76\%) e criação de 8 novos cursos de graduação, sendo 4 diurnos e 4 noturnos (UFLA, s/d).

A fim de se obter uma amostra significativa, capaz de validar a análise quantitativa do número de estudantes oriundos do ensino médio público e privado, foram levantados dados sobre as matrículas dos alunos ingressantes na UFLA a partir do primeiro semestre letivo do ano de 2005 até o segundo semestre letivo do ano de 2010, como mostra a Tabela 1.

Tabela 1: Número de estudantes oriundos do ensino médio público e particular na UFLA, por semestre, de 2005 a 2010

\begin{tabular}{|c|c|c|c|c|c|c|}
\hline & $2005 / 1$ & $2005 / 2$ & $2006 / 1$ & $2006 / 2$ & $2007 / 1$ & $2007 / 2$ \\
\hline PÚBLICO & $15,26 \%$ & $25,56 \%$ & $22,22 \%$ & $27,96 \%$ & $26,51 \%$ & $28,89 \%$ \\
\hline PRIVADO & $84,74 \%$ & $74,44 \%$ & $77,78 \%$ & $72,04 \%$ & $73,49 \%$ & $71,11 \%$ \\
\hline & $2008 / 1$ & $2008 / 2$ & $2009 / 1$ & $2009 / 2$ & $2010 / 1$ & $2010 / 2$ \\
\hline PÚBLICO & $20,33 \%$ & $27,95 \%$ & $17,22 \%$ & $33,87 \%$ & $33,18 \%$ & $25,59 \%$ \\
\hline PRIVADO & $79,67 \%$ & $72,05 \%$ & $82,78 \%$ & $66,13 \%$ & $66,82 \%$ & $74,41 \%$ \\
\hline
\end{tabular}


m base nos dados da Tabela 1, pode-se comprovar a disparidade entre o número total de alunos provenientes de escolas públicas e particulares na Universidade, ocupando o primeiro grupo uma posição de minoria. Ao longo do período analisado, observa-se pequena tendência de equilíbrio, representada pelo tímido aumento da participação dos alunos que cursaram ensino médio público.

Como forma de comparação entre o desempenho acadêmico dos alunos da UFLA, advindos do ensino médio público e privado, foi utilizado do próprio indicador da universidade, o CRA. Para melhor avaliação do panorama, calculou-se a média aritmética dos CRA's de todos os alunos, considerando as divisões de seus respectivos cursos e escola de origem, conforme mostra a Tabela 2.

Tabela 2: Média dos coeficientes de rendimento acadêmico dos alunos por curso, de 2005 a 2010

\begin{tabular}{|l|l|l|l|l|l|}
\hline & Agronomia & $\begin{array}{l}\text { Engenharia } \\
\text { Florestal }\end{array}$ & $\begin{array}{l}\text { Medicina } \\
\text { Veterinária }\end{array}$ & $\begin{array}{l}\text { Engenharia de } \\
\text { Alimentos }\end{array}$ & $\begin{array}{l}\text { Ciência da } \\
\text { Computação }\end{array}$ \\
\hline Público & 68,8 & 70,6 & 72,3 & 72,0 & 67,0 \\
\hline Privado & 63,5 & 68,6 & 70,1 & 74,2 & 64,7 \\
\hline & Administração & $\begin{array}{l}\text { Ciências } \\
\text { Biológicas }\end{array}$ & Química & $\begin{array}{l}\text { Engenharia } \\
\text { Agrícola }\end{array}$ & Zootecnia \\
\hline Público & 74,5 & 73,9 & 70,4 & 63,4 & 62,5 \\
\hline Privado & 75,5 & 74,2 & 66,7 & 60,8 & 61,1 \\
\hline
\end{tabular}

Analisando a Tabela 2, nota-se que estudantes de escolas públicas e privadas não apresentam grandes diferenças de desempenho, quando avaliados com base em indicadores meramente quantitativos. A maior diferença nas médias dos CRA's pôde ser observada no curso de Agronomia, que apresentou diferença de 5,3 entre as médias.

Os estudantes de escola pública, portanto, ainda que em minoria na universidade, em virtude das dificuldades de acesso ao ensino público, quando conseguem se inserir na Instituição, mostram-se tão capacitados quanto os demais alunos, pelo menos em termos quantitativos, ou seja, nas notas. Em alguns casos, conforme pode ser observado nos cursos de Agronomia, Engenharia Florestal, Medicina Veterinária, Ciência da Computação, Química, Engenharia Agrícola e Zootecnia, esses estudantes apresentaram CRA superior aos alunos vindos de escolas privadas. No caso em específico do curso de Administração, responsável pela maior média de CRA, a diferença manteve-se insignificante.

Faz-se importante ressaltar que a descoberta de que alunos de escola pública e privada apresentam CRA's semelhantes não nos permite concluir que os estudantes do ensino público não encontram dificuldades após seu ingresso na universidade. Nesse sentido, questionamonos se estes resultados são obtidos a partir dos mesmos esforços e das mesmas práticas e, quais outros desafios podem permear a trajetória desses estudantes.

\section{Os desafios do ensino superior para estudantes vindos de escola pública: uma análise sob a ótica daqueles que superaram as barreiras}

Ainda que seja inegável a importância de se promover o acesso de estudantes vindos de escolas públicas nas IFES, por meio de programas para expansão das universidades, como o Reuni, a permanência desses estudantes dentro da instituição ainda parece ser um dos grandes desafios. 
Uma efetiva democratização da educação requer certamente políticas para a ampliação do acesso e fortalecimento do ensino público, em todos os seus níveis, mas requer também políticas voltadas para a permanência dos estudantes no sistema educacional de ensino [...]. Não basta ter acesso ao ensino superior, mesmo sendo público, conforme indicam os resultados da pesquisa que realizei. Assim, torna-se redutor considerar indiscriminadamente os casos de estudantes que têm acesso ao ensino superior como de 'sucesso escolar' (ZAGO, 2006, p. 228).

Desta forma, apenas garantindo que estudantes de escola pública, em virtude do aumento no número de vagas, consigam se inserir dentro de uma universidade pública, não representa, por si só, uma forma de democratização do ensino superior, haja vista as dificuldades que ainda poderão permear seu processo de graduação. Tendo em vista o déficit educacional deste estudante em detrimento aos demais, este pode apresentar maior dificuldade com os conteúdos, ter que estudar mais para obter resultado semelhante ao de outros colegas, pode precisar da ajuda de monitorias ou aulas particulares para suprir suas deficiências, pode ser excluído de atividades extracurriculares, dentre outros desafios. Neste sentido, questionamonos se, de fato, esses desafios permeiam a trajetória de estudantes do curso de Administração da UFLA, oriundos de escolas públicas, cujo perfil encontra-se descrito na Tabela 3.

Tabela 3: Perfil dos alunos vindos de escola pública do curso de Administração daUFLA

\begin{tabular}{|l|l|}
\hline Sexo & $54 \%$ masculino \\
& $46 \%$ feminino \\
\hline Faixa Etária & $92 \%$ jovens de até 25 anos de idade \\
\hline Renda Familiar Mensal & $50 \%$ menor que $\mathrm{R} \$ 2.075,00$ \\
\hline
\end{tabular}

A grande maioria dos estudantes revelou ter optado pelo curso de Administração da UFLA pela alta qualidade do ensino, pela proximidade entre a universidade e sua residência e pela identificação com o curso. Entretanto, as condições sócio-econômicas dos candidatos também interferem em sua escolha, conforme pode ser observado nos relatos:

Eu sinceramente, só prestei o vestibular na UFLA porque é o próximo da minha cidade, porque se fosse em outro lugar, meu pai não teria condição de pagar hospedagem para mim, ou o transporte, nada.

No meu caso também, eu até prestei vestibular para a UFMG, prestei a primeira etapa, mas, aí eu sabia que mesmo se eu conseguisse passar eu não teria condições de me manter lá. Então, a segunda etapa eu nem fiz, nem procurei saber se tinha passado na primeira porque realmente eu sabia que não teria condições. Então, a proximidade da UFLA auxiliou muito. Se fosse mais longe eu não teria condições, mesmo sendo pública.

Quando questionados sobre a qualidade das escolas nas quais cursaram o ensino médio, 31\% dos participantes a consideraram ótima, 38\% boa, e 27\% regular. Ainda assim, 62\% afirmaram se sentir menos preparados para o vestibular, se comparados com os candidatos do ensino privado.

Se comparado com uma escola particular, para entrar na universidade, a diferença é muito grande. Não estou criticando, porque a minha escola me trouxe até aqui, com certeza. Mas, na minha qualificação, tive que "correr muito por fora".

De forma a minimizar esse sentimento de desigualdade perante os concorrentes e suprir as 
deficiências do ensino público, assim como nos mostra Zago (2006) em sua pesquisa, do total dos estudantes pesquisados no curso de Administração da UFLA, 65\% passaram por algum curso pré-vestibular antes de ingressar na universidade, sendo que destes, 88\% fizeram cursos pré-vestibulares particulares. Como resultado, $73 \%$ desses alunos em estudo prestaram o vestibular da UFLA somente uma vez.

Eu dediquei nos meus 6 meses de cursinho o que eu não dediquei nos meus 3 anos de ensino médio, praticamente. Então, o problema não era só da escola, mas também do meu comportamento, mas, porque há a diferença do cursinho ser pago, então quando você vê o dinheiro sendo gasto, querendo ou não você dedica mais. (...) Então eu acho que quando você está investindo, você quer retorno. Eu acho que isso ajuda demais.

Dados do relatório do INEP, que avalia o desempenho de estudantes do ensino médio por meio de indicadores disponibilizados pelo SAEB - Sistema Nacional de Avaliação da Educação Básica, denunciam o perfil dos alunos caracterizados como tendo desempenho "crítico" ou "muito crítico" em português e matemática: "76\% estão matriculados no ensino noturno, 48\% conciliam trabalho e estudo, 84\% estão acima da idade considerada ideal e, mais importante, 96\% estudam em escolas públicas" (SAMPAIO e GUIMARÃES, 2009, p. 46).

Em relação aos estudantes que participaram da pesquisa, observa-se também que, mesmo tanto êxito no ingresso à universidade, ao longo dos estudos no curso pré-vestibular, esse déficit educacional, apontado pelo INEP, ainda prejudicava o desempenho dos alunos do ensino público:

Fiz um ano de cursinho e encontrei muita dificuldade, muita coisa que eu não tinha visto na escola pública, principalmente nas disciplinas de História, Geografia, Química, eu tive bastante dificuldade.

Quando o professor dava a aula, muitas vezes eu não entendia nada que o professor falava. Aí o que acontecia, eu olhava pro lado e tinha pessoas que estavam cochilando, "abrindo a boca de sono" de tão fácil que era pra elas, por que era apenas a fase introdutória da matéria, e pra mim já tinha dificuldade, não conseguia acompanhar o professor. Eu tinha que "correr por fora", então, eu comecei a freqüentar a monitoria, a pegar experiências com alunos que já haviam passado no vestibular. Foi assim que eu comecei a adquirir hábitos de um bom estudante, por que a cultura de escola pública não exige tanto. Então eu percebia a diferença, por isso que te falo que a diferença é nítida (...). O concorrente da particular já estava revisando a matéria dada, eu estava estudando a base dela para aprender como se fazia. Quer dizer, eu já saia perdendo.

Quando questionados sobre a maior dificuldade para estudantes do ensino público, 88\% dos respondentes apontaram "passar no vestibular" como o maior obstáculo, sendo que para 77\% deles a origem escolar pode impor determinados desafios aos estudantes. Esta dificuldade, conforme observado, deriva dos diferentes problemas peculiares ao ensino público, o que corrobora as ideias já apontadas por Vasconcelos (2004):

Eu acredito que na escola pública existam vários desafios. Lembrando lá o primário e o fundamental, a primeira coisa é a falta de material e estrutura. Faltavam laboratórios, a gente não tinha onde praticar, além de qualificação e motivação dos professores, muitas vezes a gente tinha que "correr atrás". Eu lembro que quando eu fiz o fundamental tinha época que faltava livro, faltava material ou mesmo professor. 
Às vezes o professor tem motivação para trabalhar, ele quer trazer uma coisa diferente para dentro de sala de aula, mas não tem como, porque a escola não oferece estrutura pra ele (...), não tem sala adequada, com acesso a internet, ou então não tem material, tipo folhas, a escola não disponibilizava. Até a prova mesmo, os alunos tinham que contribuir para imprimir ouxerocar.

Onde eu estudei, eu acho que o material era muito fraco, até tinham bons professores, alguns que davam aula em cursinho e em escolas particulares, mas eles tinham que seguir o material que a escola disponibilizava, não podiam trazer de outra escola.

A grande quantidade de alunos em sala de aula também é apontada como um fator que afeta negativamente o aprendizado no ensino público, haja vista a dificuldade de o professor atender individualmente cada aluno, auxiliando-os em suas dificuldades, o que, conforme relatado, faz com o que alunos com maior dificuldade não consigam acompanhar o andamento da turma e alunos com maior facilidade tenham seu rendimento limitado pelo rendimento dos outros colegas.

Os participantes manifestaram certa indignação com a falta rigidez por parte das escolas públicas, que cobram pouco de seus alunos, o que faz com que a qualidade do ensino seja prejudicada:

Infelizmente a escola pública não é tão rígida quanto à particular (...). Eu lembro que na minha época, a escola tava passando por um processo de mudança do Governo Federal, questões de quesitos de avaliação, eu lembro que era bem mais difícil. Eu sei que, por exemplo, na minha turma, teve ano que eram reprovadas 4, 5 pessoas, aí no outro ano não reprovava ninguém. É porque todo mundo era bom? Não, é porque o governo começou a "meio que vendar os olhos e ir empurrando" (...). Pra você ser reprovado, você tinha que fazer umas 15 provas lá e chegava num ponto que chegava a ser ridícula a matéria que eles cobravam, então, ninguém era reprovado.

E é isso mesmo, na escola pública você faz uma prova, duas provas, recuperação, substitutiva, e tem ainda o tal do provão, aí não passa, tem ainda o "re-provão" [risos], é dada muita "colher de chá" para o aluno. Aí o "cara" se desmotiva, acha que não precisa estudar tanto pra passar.

A falta de motivação dos professores, em virtude dos baixos salários, também foi revelada como um agravante na qualidade do ensino público. Para os participantes, professores desmotivados implicam em alunos desmotivados, que, por sua vez, só faz aumentar o desinteresse do professor, fazendo deste processo um ciclovicioso:

Já tive professor que era professor de escola pública e particular, e um amigo meu que teve aula com ele na escola particular disse que ele dava um show na escola particular. Mas, chegava na escola pública, que o salário era menor, ele dava aquela aulinha só para "defender" o salário básico dele e era totalmente desmotivado. Então, quer dizer, se o educador passa o mínimo para os alunos, infelizmente esses alunos serão prejudicados. Então é essencial a motivação, o salário, porque infelizmente ninguém trabalha por esporte, então o salário diz tudo.

Tem professor que trabalha três turnos, não tem nem tempo de preparar a aula. Ele trabalha de manhã, à tarde e a noite. A noite é a hora que ele vai pegar o ensino médio, ele tá super cansado, ele pega uma revista põe debaixo do braço e manda os alunos lerem três páginas lá e "acabou minha aula". E os alunos já estão cansados também, né, vão ler e fingir que foi dada a aula. 
Alunos desmotivados no ensino público são, muitas vezes, o reflexo das dificuldades sócioeconômicas de suas famílias, que impede que esses estudantes possam se dedicar integralmente aos estudos, como a grande maioria dos estudantes do ensino privado. Desta forma, mais uma vez a desigualdade social impõe seus limites sobre os indivíduos de classe social mais baixa, que precisam trabalhar para se sustentar e sustentar suas famílias, mas que, por outro lado, precisam do estudo para conseguir trabalhar.

Eu trabalhei desde a minha sexta série. Então, isso pesa muito e é muito difícil, porque eu já tinha trabalhado o dia todo, chegava na aula 6, 7 horas da noite, como se diz, "se vira", tem que "tirar" motivação mesmo.

Eu tirei meu Ensino Médio com vinte e dois anos, quer dizer, isso já sai uns 5,6 anos fora do "normal aí". Então, quer dizer, você atrasa os estudos e também, depois até para entrar em uma universidade também fica difícil, devido ao fato de eu não ter condições de pagar um cursinho (...). Você trabalha o dia inteiro, à noite, o seu corpo quer cama. Então, eu ia tentar ir para a escola (...). Ou seja, aumenta até o tempo para entrar na universidade.

O papel das escolas de divulgar e despertar nos alunos o interesse pela universidade foi outro aspecto comentado na discussão. Para os estudantes, a escola pública deveria incentivar mais seus alunos a participar dos processos seletivos e despertar nesses a motivação para tentálos. Às universidades caberia também a iniciativa de divulgar mais suas oportunidades e atrair esses estudantes.

Uma coisa que eu achei interessante quando estava no ensino médio, foi que o PET foi lá na minha escola falar sobre a UFLA. Eu acho que essa interação da universidade com a escola é muito interessante, porque se tiver alguém que motive, que fale, que venha da universidade e informe, mostre que se dedicar um pouco a mais é possível (...), será retirada essa cultura de que não é possível passar pelo vestibular, "sou de escola pública, vai dar tudo errado, eu não vou passar (...)". Mas, a partir do momento que a pessoa vê que é possível passar, melhorar de vida, ajudar os familiares, aí tudo começa a mudar.

Um projeto fantástico que o governo criou é o BIC Júnior. Na minha turma todos que fizeram o BIC Júnior passaram no vestibular (...). O projeto vem trazer essa deixa de conhecimento da universidade, mostrar que a gente pode.

Porém, a existência de programas para estudantes do ensino médio, como o Processo de Avaliação Seriada (PAS) e o Programa de Bolsas Institucionais de Iniciação Científica Júnior (BIC Júnior), não representa, para a maior parte dos alunos, uma ferramenta de auxílio ao ingresso na universidade. Apenas uma pequena parcela desses estudantes teve a oportunidade de participar desses programas, sendo a falta de divulgação nas escolas a causa principal deste desinteresse.

No meu caso não tinha incentivo nenhum por parte da escola, nem propaganda, nem nada. Nem os alunos que já passaram no vestibular, nunca foram citados como exemplo. O PAS também foi muito pouco divulgado, a gente ficou sabendo porque alunos que fizeram o PAS antes disseram pra gente, aí depois que a gente fez a primeira etapa, que a escola começou a incentivar.

A esse respeito muito foi discutido sobre uma "cultura desmotivadora" existente nas escolas públicas. Segundo os próprios participantes, é comum entre alunos da rede pública não tentar o vestibular, simplesmente por acreditar que não tem condições de concorrer com os outros candidatos: 
Eu penso assim, tem a dificuldade em entrar, isso realmente existe, mas falta um pouco de querer, de motivação por parte do aluno. Isso não porque o aluno não quer, à toa, tem motivos. Não quer por quê? Porque geralmente o aluno de escola pública é tachado: "ah, ele não consegue entrar em uma universidade". Na minha turma, isso aconteceu. Muitos não tentaram; não passaram porque não tentaram, eu tenho certeza que muitos tinham condições de passar, mas porque tem essa idéia: "ah eu sou de escola pública, eu não vou conseguir passar numa federal, não tenho qualidade de concorrer com um aluno de escola particular". Faltou motivação por parte de um aluno e incentivo. Pelo aluno ser tachado assim, a sociedade tachar ele como "o aluno que não consegue passar", isso já contribui, onde ele fica desmotivado. Para muitos eu perguntava "você não vai prestar o vestibular?" e ele falava, "não, pra que? Eu não vou conseguir, porque que eu vou tentar fazer isso?" (...).

Essa mesma situação foi mostrada por Zago (2006) em sua pesquisa. Muitos estudantes do ensino médio de escolas públicas possuíam pouca informação sobre o vestibular e a formação universitária. Em diálogo com Silva (2003 apud ZAGO, 2006), a autora afirma a ausência de um "capital informacional" sobre o sistema do vestibular, os cursos e as instituições que os oferecem.

Ainda nesse contexto de dificuldades enfrentadas pelos estudantes de escolas públicas, podese afirmar, a partir de seus depoimentos, que a falta de apoio e valorização familiar também se constitui uma barreira ao acesso nas universidades, uma vez que, após concluírem o ensino médio, os jovens precisam trabalhar para se sustentar. Por outro lado, quando há incentivo por parte dos familiares, em especial, quando alguém já freqüentou o ensino superior, a motivação é maior:

Às vezes, não é só falta de motivação, um pouco também cultural dos familiares, por que eu tenho várias amigos que falam que não precisam fazer faculdade para trabalhar e ter um bom emprego.

Na minha família não tem ninguém no ensino superior (...). Eu sou a primeira e já incentivei gente mais velha que tinha interesse e que agora tá correndo atrás de ensino superior.

Eu acho que falta muito uma referência. No meu caso, tenho um irmão mais velho que já fazia faculdade e isso me influenciou bastante.

Além disso, a carga horária inferior a das escolas privadas é um fator que incomoda os alunos, uma vez que estes sentem que têm menos tempo para ver os conteúdos, que são trabalhados de maneira mais superficial ou, muitas vezes, não o são, o que se reflete na sensação de despreparo perante os estudantes do ensino privado:

Minha formação para o vestibular perante o aluno de escola privada era defasada, por que tinha matéria que eu nunca vi. E aí, eu vejo que o PAS surge para auxiliar de uma forma muito interessante. Quando ele divulgou o cronograma de matérias, eu vi que no meu $1^{\circ}$ ano eu só tinha feito a metade do cronograma. Enquanto isso, os alunos de escola particular já haviam feito tudo. Aí, o que eu comecei a fazer: comecei a cobrar os meus professores em cima do cronograma do PAS.

Além de terem matérias que você nem via, tinham outras que eram passadas muito superficialmente, principalmente matérias da área de exatas, as matérias mais difíceis, que sempre são cobradas no vestibular. (...) Então, acabava que essas matérias ficavam como sendo as últimas do período, resultado, você deixa pro final, e ela nunca é dada, vai acumulando matéria atrasada, e chegava no 
final e não dava tempo de serem vistas as que ainda não foram passadas. Quando dava tempo, você pegava uma questão e achava, por exemplo, "ah, função é fácil". Aí você pegava uma questão dessas no vestibular e você não sabia nem mexer, por quê? Porque era ensinada uma questão muito superficial, muito básica no ensino médio, aí simplesmente você não tinha base. Eu aprendi função, logaritmos, agrupamentos, isso tudo eu aprendi no cursinho, porque em escola pública, realmente, você tem uma ideia do que seja, mas aprender você não aprende mesmo não.

Corroborando com a assertiva de que o preparo para o vestibular representa a maior dificuldade desses estudantes, 65\% dos respondentes afirmaram que a formação média pública não lhes prejudica dentro da universidade, haja vista seu empenho nas disciplinas e a dissociação entre o conhecimento apreendido no ensino médio e na universidade. Desta forma, ainda que as diferenças entre alunos de escola pública e privada se mostrem nítidas quando analisados em profundidade, essas disparidades não se mostram tão perceptíveis no cotidiano dos estudantes, de acordo com suas percepções. Em atividades rotineiras, como provas e trabalhos, apenas $12 \%$ dos respondentes afirmaram conseguir identificar a origem do aluno pelo seu desempenho. A maioria só sabe da origem escolar do colega quando é estabelecida alguma relação interpessoal mais próxima, sendo essa informação sabida apenas pelo convívio.

Não sei de todo mundo concorda, mas quando a gente entra na universidade isso se nivela muito (...) e se você me pergunta "quem é de escola pública na sua sala?", eu não saberia responder, por que aqui se nivela pela dedicação.

Acho que esse nivelamento vem, porque a partir do momento que você entra aqui, os recursos são iguais para todo mundo, a estrutura, então acabou a diferença (...). As matérias iniciais do curso são as que exigem o ensino médio, aí naquele momento de introdução, aí sim existe diferença, mas, depois quando se passa pelo $2^{\circ}$ período, se não fala mais quem veio de um lugar e quem veio de outro não.

Porém, apesar dessa percepção dos estudantes pesquisados, é possível afirmar que as dificuldades educacionais são superadas depois que conseguem o acesso à universidade? Basta apenas a dedicação pessoal para que as todas as dificuldades enfrentadas anteriormente desapareçam? Permaneceriam apenas os desafios financeiros, conforme afirmam os estudantes?

Aqui dentro da UFLA, assim, o desafio seria mais econômico-financeiro. Eu perdi meu pai eu tinha quinze anos e, não só aqui, antes de vir pra cá, (...) em casa é assim: se trabalhar, come, se não trabalhar, fica com fome. Então, eu cheguei aqui, mas eu tenho que me manter, não posso ficar à toa, eu tenho que trabalhar, condição socioeconômico-financeira baixa, né?

Bom, a minha dificuldade também foi mais financeira, assim, porque eu venho de família baixa renda, eu tive praticamente que me auto-sustentar, né? Então, (...) bolsa-atividade que me ajudou.

A Universidade é pública, mas, a gente tem gastos que eu nunca tinha imaginado (...).

A Universidade disponibiliza, né, mas ainda é pouco, as bolsas atividade. (...) tem dificuldade, mesmo com a bolsa, mesmo com a alimentação sendo mais barata para quem é aluno de baixa renda, mesmo assim ainda tem essas dificuldades, (...). 
Ainda que com muitas dificuldades, os estudantes não esperam políticas públicas que possibilitem facilidade para as minorias sociais na entrada no ensino superior. Ao contrário, se preocupam a perda da qualidade do ensino caso isso venha a acontecer. A esse respeito, a política de cotas e o Reuni foram alvo de discussões por parte dosparticipantes:

Você pode perceber que com o Reuni está havendo mudanças. Mas eu sou contra, por que o desafio não é só entrar na faculdade, mas sim se manter nela. Eu percebo que muitas pessoas que estudam comigo não merecem estar aqui. Eu acho que facilitar a entrada com o aumento de vagas é pior, é melhor formar poucos com qualidade do que muitos reduzindo a qualidade. Há a formação de muitas pessoas desinteressadas e estas se tornam maus profissionais.

Tem hora que dá raiva: o que você tá fazendo aqui? Está aqui pra quê? Hoje mesmo um amigo meu veio pra faculdade sabia que tinha aula e não entrou. Por que ele estava aqui? Se é sua obrigação, se ele veio pra estudar, porque que ele não está estudando? Não é só entrar aqui dentro não, por que entrar é fácil, agora vamos ver lá na frente, por isso que tanto profissional não é bom. Por que saiu daqui do jeito que entrou.

Podemos afirmar que essa falta de compromisso com a universidade pública é decorrente da entrada de estudantes vindos de escolas públicas, de classes sociais mais baixas ou até mesmo de afrodescendentes? Não estariam essas pessoas assumindo sua vaga com maior responsabilidade e dedicação em relação àqueles estudantes que poucos desafios enfrentaram para entrarem em uma universidade pública?

Ainda segundo os estudantes, as desigualdades entre alunos de escolas públicas e privadas também não se estabelecem como barreiras à inserção dos primeiros em atividades extracurriculares, o que faz com que todos tenham acesso às mesmas oportunidades. Dentre todos os respondentes, $85 \%$ desenvolvem ou já desenvolveram alguma atividade extracurricular dentro da universidade, como Programa de Educação Tutorial (PET), Empresa Júnior, Monitoria e Iniciação Científica, sendo que a maioria das atividades citadas oferece benefício de bolsa. Esses estudantes ainda colocaram que não sentiram diferenças perante os colegas oriundos de escola privada durante o processo de seleção.

E a dedicação aos estudos e a abdicação de interesses pessoais por parte desses estudantes para que consigam se inserir nessas atividades acadêmicas? Podemos afirmar que acontece da mesma forma se olharmos o cotidiano de alunos vindos de escolas privadas, geralmente, com melhores condições socioeconômicas e culturais?

Do total de alunos pesquisados, $73 \%$ não acreditam que tiveram que estudar mais que um aluno de escola particular para obter um bom desempenho. Porém, 58\% disseram frequentar ou ter frequentado aulas particulares e/ou monitorias. Quase a metade dos respondentes (46\%) foi reprovada em alguma disciplina do curso, sendo as disciplinas que mais reprovam as que envolvem a cálculos matemáticos, como Cálculo I, Estatística e Matemática Financeira. Essa constatação encontra respaldo na afirmativa desses alunos de que os cálculos matemáticos representam a atividade de maior dificuldade de aprendizado, seguida pela leitura e escrita, respectivamente. Os respondentes apontaram como a principal causa de suas reprovações o rigor em excesso do professor e a dificuldade do conteúdo da disciplina.

Uma observação relevante diz respeito aos $25 \%$ dos estudantes que afirmaram sentir maior dificuldade para alcançar aprovação em algumas disciplinas do curso, como Matemática, Filosofia e Sociologia, em detrimento aos estudantes de escola particular. Deve-se salientar que tais ciências envolvem conteúdos básicos (conceituais, procedimentais e atitudinais) que 
deveriam ter sido apreendidos no ensino médio, provavelmente vistos pelos estudantes de escola privada e omitidas pelo ensino público. Teriam os estudantes de escolas públicas desenvolvido as habilidades de leitura, interpretação, compreensão, criticidade, dentre outras, tão necessárias na consolidação da formação no ensino superior?

Por fim, os estudantes fizeram questão de acrescentar que, de forma geral, o fator determinante para um bom desempenho de qualquer aluno durante o curso é o empenho. Desta forma, desde que um indivíduo seja esforçado e dedicado, a conclusão de sua graduação com sucesso torna-se possível, independente da sua origem escolar. Em contrapartida, os próprios estudantes ressaltaram a importância de uma ação conjunta entre o Governo e as universidades.

Assim, precisamos nos dedicar mais? Sim. Mas o governo ainda precisa ter um olhar maior perante todo o ensino fundamental, que é a nossa base, entendeu? Acho que é essa a proposta que poderia ficar.

Que a UFLA se preocupe mesmo em abrir as portas, se apresentando para as escolas públicas: "olha, tem como, sabe... o cronograma tá aqui, tem o site, tem os lugares, tem os panfletos, sabe...". Então, é divulgar mesmo para que os alunos tenham meios, meios para que se possam lutar, correratrás.

Considero que a universidade é muito fechada, não retribui pra sociedade o dinheiro que é investido nela. É necessário haver mais projetos de extensão, e, assim, a universidade proporcionar mais benefícios à sociedade. Hoje o retorno para sociedade é muito pouco, a gente percebe que há mais o retorno individual, de capacitação da pessoa, que eu até concordo que seja importante, mas é preciso pensar mais no coletivo, já que a sobrevivência da universidade depende dele.

É preciso haver maior divulgação sobre o que é criado aqui dentro, muitas vezes, teses de mestrado, monografias e pesquisas são feitas e não são divulgadas para trazer alguma solução para o problema. O material, muitas vezes, vai para a biblioteca e lá fica esquecido, sem trazer algum benefício.

A despeito de todos os desafios apontados, podemos afirmar que o sucesso escolar é determinado apenas pelo empenho individual? Considerando as dificuldades pelas quais passam até entrarem na universidade e durante os primeiros períodos da graduação, esses estudantes seriam mais responsáveis, dedicados e valorizam mais sua condição de estudante de uma universidade pública federal? Acreditamos que sim, o que confirma o que muitos apontaram. Porém, para além das dificuldades financeiras, as questões sociais, como as de gênero, raça/etnia, orientação sexual, religião e outros marcadores sociais, também não constituiriam barreiras "invisíveis" às conquistas que a formação superior oferece?

\section{Conclusão}

A formação do estudante de escola pública é permeada por algumas dificuldades peculiares a esse tipo de ensino. Dentre os principais problemas, destacam-se a falta de estrutura e recursos, a desmotivação dos professores por conta dos baixos salários, o desinteresse dos alunos, seja pelo cansaço físico, ou pela falta de perspectivas para o futuro, que é difundida por meio de uma cultura de interiorização dos alunos do ensino público. Não obstante, o distanciamento entre as escolas e a universidade e a falta de divulgação das oportunidades existentes fazem do ensino superior uma realidade distante para a maioria desses estudantes.

Ainda assim, apesar de todas as dificuldades, com esforço e dedicação, tendo que "correr um pouco mais atrás", muitos egressos do ensino público conseguem ter acesso ao ensino 
superior, sendo que, depois de inserido, estes conseguem ter o mesmo padrão de aprendizagem daqueles que vieram de escola privada. Entretanto, como principal desafio neste nível educacional apontado pelos participantes, o aluno de escola pública continua tendo que enfrentar problemas econômico-financeiros que, até certo ponto, exigem ainda mais esforço destes estudantes. Neste sentido, iniciativas em prol da permanência destes estudantes nas universidades, como a concessão de bolsas, fazem-se fundamentais.

Porém, podemos afirmar que, ao saírem da universidade, com êxito, as diferenças entre estudantes que vieram do ensino público e do ensino privado serão extintas? Haverá outros desafios a serem transpostos por esses estudantes, cuja condição socioeconômica é mais baixa? Terão eles as mesmas oportunidades de emprego? Terão desenvolvido capital cultural suficiente para se inserirem na carreira acadêmica, caso hajainteresse?

Assim, além de medidas conjuntas entre o governo e a universidade que visem a educação, tanto básica como superior, outras políticas públicas precisam caminhar junto às educacionais a fim de que, ao entrarem no mercado de trabalho, os estudantes egressos tenham as mesmas oportunidades.

Com certeza, a iniciativa dos próprios alunos que passaram por esses entraves também é fundamental como forma de motivação e divulgação aos demais. Os relatos desses jovens devem servir de exemplo para amigos, familiares, vizinhos, bem como para toda comunidade, para mostrar que é possível romper as barreiras e criar condições para uma vida melhor.

Esta pesquisa representa, portanto, uma tentativa de incitar a continuidade da discussão sobre formas de se garantir a igualdade de acesso e permanência no ensino superior a todos os estudantes brasileiros.

\section{Referências}

Instituto Nacional de Estudos e Pesquisas Educacionais. IDEB - Resultados e Metas. Disponível em: < http://sistemasideb.inep.gov.br/resultado/>. Acesso em:28/04/2011.

MARCON, Frank. Do ensino básico ao ensino público superior: distorções sociais e étnicoraciais em Sergipe. Revista Fórum Identidades, ano 2, v. 3, p. 19-32, jan-jun. 2008.

MEC. Reuni. Disponível em: <http://reuni.mec.gov.br/>. Acesso em: 02/05/2011

MEC/INEP. Resumo Técnico Censo da Educação Superior de 2009. Brasília, 2010.

MEC/INEP. Resumo Técnico Censo Escolar de 2010 (versão preliminar). Brasília: dezembro de 2010.

MEC. Reuni 2008 - Relatório do Primeiro Ano. Brasília: 30 de outubro de 2009. Disponível em: http://reuni.mec.gov.br. Acesso em: 02/05/2011

BUARQUE, Cristovam. A universidade numa encruzilhada. Trabalho apresentado na Conferência Mundial de Educação Superior + 5, UNESCO, Paris, 23-25 de junho de 2003.

DIAS, Cláudia Augusto. Grupo focal: técnica de coleta de dados em pesquisas qualitativas. Informação e Sociedade: Estudos, v.10, n.2, 2000. Disponível em < http://periodicos.ufpb.br/ojs2/index.php/ies/article/view/330>. Acesso em:02/06/2011.

GONDENBERG, Mirian. A arte de pesquisar: como fazer pesquisa qualitativa em Ciências Sociais, 10 ${ }^{\mathrm{a}}$ ed., Rio de Janeiro: Record, 2007.

MARCON, Frank. Do ensino básico ao ensino público superior: distorções sociais e étnico- 
raciais em Sergipe. Revista Fórum Identidades, ano 2, v. 3, p. 19-32, jan-jun, 2008.

NEVES, Clarisa Eckert Baeta; RAIZER, Leandro; FACHINETTO, Rochele Fellini. Acesso, expansão e equidade na educação superior: novos desafios para a política educacional brasileira. Sociologias. Porto Alegre, ano 9, n. 17, jan.-jun., 2007, p. 124-157.

ORTEGA, Eliane Maria V. O ensino médio público e o acesso ao ensino superior. Estudos em Avaliação Educacional. São Paulo, Fundação Carlos Chagas, n. 23, p. 153-176, jan./jun. 2001.

PINTO, José Marcelino de Rezende. O acesso à educação superior no Brasil. Educação \& Sociedade. Campinas, v. 25, n. 88 especial, p. 727-756, 2004.

VASCONCELOS, Celso do Santos. Coordenação do trabalho pedagógico: do projeto políticopedagógico ao cotidiano da sala de aula. São Paulo: Libertad, 2004.

VASCONCELOS, Simão Dias; LIMA, Kênio Erithon Cavalcante. Inclusão social e acesso às Universidades Públicas: o programa Professores do Terceiro Milênio. Estudos em Avaliação Educacional, São Paulo, s.n., n. 29, p. 67-86, jan.-jun. 2004.

SAMPAIO, Breno; GUIMARÃES, Juliana. Diferenças de eficiência entre ensino público e privado no Brasil. Economia aplicada, São Paulo, v. 13, n. 1, p. 45-68, jan.-mar. 2009.

SOARES, Maria Susana Arrosa. 0 acesso à educação superior e sua cobertura demográfica. In: SOARES, Maria Susana Arrosa (coord.). A Educação Superior no Brasil. Porto Alegre, 2002.

UNIVERSIDADE FEDERAL DA BAHIA. Perfil Sócio-Econômico dos Candidatos Inscritos e Classificados no Concurso Vestibular da UFBA: 2001-2004. Salvador: UFBA/ PROPLADSIE, 2005. Disponível em: http://www.cpa.ufba.br/relatorios.html. Acesso em 04/04/2011.

UNIVERSIDADE FEDERAL DE LAVRAS. Disponível em: <www.ufla.br> Acesso em: 28/06/2011.

ZAGO, Nadir. Do acesso à permanência no ensino superior: percursos de estudantes universitários de camadas populares. Revista Brasileira de Educação, v. 11, n. 32, maio-ago 2006. 